\title{
Dielectric Relaxation studies of Methyl acetate with 2-Alkoxyethanols using Time Domain Reflectometry Technique
}

\author{
S. Kumar ${ }^{* 1}$, L. Guganathan ${ }^{1}$, M. Malathi ${ }^{2}$, A. Mohan ${ }^{3}$, R. Amalanathan ${ }^{1}$ \\ ${ }^{1}$ Department of Physics, Annamalai University, Annamalainagar, India \\ ${ }^{2}$ Materials Physics Division, School of Advanced Sciences, VIT, University, Vellore, India. \\ ${ }^{3}$ Faculty of Metallurgical and Energy Engineering, Kunming University of Science and Technology, Kunming, China. \\ "Corresponding Author: drskumar1962@gmail.com, Tel.: +91-9842012369
}

Available online at: www.isroset.org

Received:10/Oct/2018, Accepted:22/OCt/2018, Online: 31/Oct/2018

\begin{abstract}
Complex Dielectric spectra of Methyl acetate (MA) with 2-Alkoxyethanols like 2-methoxyethanol (2-ME), 2-ethoxyethanol (2-EE), 2-butoxyethanol (2-BE) for various concentrations over the frequency ranges from $10 \mathrm{MHz}$ to $20 \mathrm{GHz}$ at $308.15 \mathrm{~K}$ were recorded using Time Domain Reflectometry (TDR). The dielectric constant, dielectric permittvity and dielectric loss were obtained from the TDR measurement. The molecular interaction parameters like relaxation time, Kirkwood correlation factors, Bruggeman factor, excess dielectric constant, excess inverse relaxation time and excess Helmholtz free energy of activation were also calculated. This study gives the information about the nature of molecular interaction between the participating liquid molecules.
\end{abstract}

Keywords - Complex Dielectric spectra, Relaxation time, Methyl acetate, 2-Alkoxyethanols, Time Domain Reflectometry.

\section{INTRODUCTION}

When two liquids of different chemical properties are mixed together, it results into a state which has properties widely different from the constituent liquids. Understanding such behavior, in particular the molecular interaction present between the pure liquids and solutions becomes a necessity as they find a variety of applications in industries. The study of 2Alkoxyethanols is important because they are widely used as solubilizing agents in many industries as well as in pharmaceutical and plastic products. Esters are important because they have distinctive flavor and pleasing odor due to which they are widely used in favor and fragrance industries and is also used as plasticizers to get specific thermo characteristics [13].

The study of mixing behavior of mixtures containing Alkoxyethanols and Esters is useful for many industrial applications. Biodiesel fuels typically contain mono alkyl, often methyl and ethyl, esters of long-chain fatty acids, derived from vegetable oils or animal fats. In general combustion performance is influenced by the chemical nature of the esters in the biodiesel fuel and their structural features, including the length of the alkyl chain and their degree of saturation and branching [4-7].

2-Alkoxyethanols are used as a solvent for many different purposes such as varnishes, dyes, and resins. 2-Alkoxyethanols are very interesting class of solvent having ether component. It has both proton accepting and donating ability. They are aliphatic in nature $[8,9]$. Systematic measurements on binary liquid mixtures comprising of 2-Alkoxyethaols + Esters have been carried out in our laboratory. This study was carried out to understand the inter molecular interactions present between Alkoxyethanols and Esters for different concentrations at $308.15 \mathrm{~K}$, over the frequency range $10 \mathrm{MHz}$ to $20 \mathrm{GHz}$, using time domain reflectometry.

\section{MATERIALS}

The Chemicals utilized for this work were Methyl acetate (MA), 2-methoxyethanol (2-ME), 2-ethoxyethanol (2-EE), 2-butoxyethanol (2-BE) supplied by Loba chemicals (purity >> 99\%) AR-grade and were used without further purification. The purity of chemicals were tested by comparing their densities and refractive indices from 
the literature values. The digital electronic balance (Adventurer Ohaus AR2140) was used for the mass measurement with an accuracy of $\pm 0.0001 \mathrm{~g}$.

\subsection{METHODS}

The refractive indices for the prepared mixtures were measured by using Abbe's refractometer (SIPCON model) with sodium $\mathrm{D}$ line at $308.15 \mathrm{~K}$. Density measurement was carried out using specific gravity bottle. The water circulation bath was provisioned using a temperature controller system (ESCY IC 201 model), accuracy of 0.5 K. Perkin Elemer RXI FT-IR spectrophotometer was used to find molecular functional group and vibrational modes analysis. The complex dielectric spectra for pure and binary mixtures were determined by using TDR Instrument.

The densities of the pure compounds were determined using a DMA $4500 \mathrm{M}$ (Anton Paar) vibrating-tube digital densitometer. The sample cell was calibrated with air and double distilled water before measurements. The accuracy of the measured density and temperature was $\pm 1 \times 10^{-2} \mathrm{~kg} \cdot \mathrm{m}^{-3}$ and $\pm 0.01 \mathrm{~K}$, respectively. Refractive indices were measured with an accuracy of $\pm 1 \mathrm{x}$ $10^{-5}$. The temperature of the refractometer was controlled by a thermostat system (ESCY IC 201) with an accuracy of $\pm 0.5 \mathrm{~K}$.

The complex dielectric spectra were measured using Time Domain Reflectometry (Agilent infiniium DCA-J 86100A with sample oscilloscope HP 54754A). A repetitive fast 39 picoseconds (ps) rising time step voltage pulse was fed through a $50 \Omega$ impedance semi-rigid slim probe having pin length $0.14 \mathrm{~mm}$. Reflected pulse without sample $R_{1}(t)$ and with sample $R_{x}(t)$ were recorded in a 2 ns time window and digitized into 1200 points. The frequency dependent complex spectra were obtained from reflection coefficient spectra. The detailed TDR data analysis procedure was reported [10, 11]. The thermostat (ESCY IC 201) was used to maintain constant temperature in the sample cell with an accuracy of $\pm 0.5 \mathrm{~K}$.

\section{RESULTS}

Table 1: Comparison of Experimental Densities $(\rho)$ and Refractive Indices $\left(n_{D}\right)$ Values of Pure compounds with Literature values at $308.15 \mathrm{~K}$

\begin{tabular}{|c|l|l|l|l|l|l|l|l|}
\hline & \multicolumn{7}{|c|}{ Compounds } \\
\cline { 2 - 9 } & \multicolumn{3}{|c|}{$\begin{array}{l}\text { Methyl acetate } \\
\text { methoxyethanol }\end{array}$} & \multicolumn{2}{|l|}{ 2-ethoxyethanol } & \multicolumn{2}{|l|}{ 2-butoxyethanol } \\
\cline { 2 - 9 } Properties & Exp. & Lit. & Exp. & Lit. & Exp. & Lit. & Exp. & Lit. \\
\hline $\boldsymbol{\rho}\left({\left.\mathbf{g} \cdot \mathbf{c m}^{-3}\right)}\right)$ & 0.9150 & $0.9152^{12}$ & 0.9510 & $0.9510^{13}$ & 0.9160 & $0.9160^{15}$ & 0.8870 & $0.8889^{16}$ \\
\hline $\mathbf{n}_{\mathbf{D}}$ & 1.3550 & $1.3550^{12}$ & 1.3960 & $1.3949^{14}$ & 1.4020 & $1.4017^{16}$ & 1.4130 & $1.4132^{16}$ \\
\hline
\end{tabular}

Table 2: Dielectric constant $\left(\varepsilon_{0}\right)$ and relaxation time $(\tau)$ of pure liquids at $308.15 \mathrm{~K}$

\begin{tabular}{|l|c|c|c|c|}
\hline \multirow{2}{*}{ Compounds } & \multicolumn{2}{|c|}{$\boldsymbol{\varepsilon}_{\mathbf{0}}$} & \multicolumn{2}{c|}{$\boldsymbol{\tau}(\mathbf{p s )}$} \\
\cline { 2 - 5 } & Experimental & Literature & Experimental & Literature \\
\hline Methyl acetate & 6.19 & $6.49^{17}$ & 7.99 & $8.87^{17}$ \\
\hline 2-Methoxyethanol & 16.06 & $15.82^{18}$ & 29.20 & $25.85^{18}$ \\
\hline 2-Ethoxyethanol & 15.46 & $15.8(313.15 \mathrm{~K})^{19}$ & 36.46 & $36.6(313.15 \mathrm{~K})^{19}$ \\
\hline 2-Butoxyethanol & 9.21 & - & 51.93 & - \\
\hline
\end{tabular}

The experimentally measured values of densities $(\rho)$ and refractive indices $\left(\mathrm{n}_{\mathrm{D}}\right)$ of pure Methyl acetate (MA) and 2Alkoxyethanol liquids at $308.15 \mathrm{~K}$ were tabulated in Table 1 . The complex permittivity spectra $\varepsilon^{*}(\omega)$ of MA with 2 Alkoxyethanols were recorded in the TDR instrument in the frequency range of $10 \mathrm{MHz}$ to $20 \mathrm{GHz}$ using Tektronix model no. DSA8200 Digital Serial Analyzer at $308.15 \mathrm{~K}$. The complex permittivity $\varepsilon^{*}(\omega)$ values are fitted with Debye equation and the dielectric quantities were derived. The static dielectric constant $\left(\varepsilon_{0}\right)$ and relaxation time $(\tau)$ values of pure liquids are listed in Table 2 and their literature values are also given and compared.

The dielectric quantities like static dielectric constant $\left(\varepsilon_{0}\right)$, dielectric constant at high frequency $\left(\varepsilon_{\infty}\right)$, relaxation time $(\tau)$ and activation energy for relaxation time $\left(\Delta \mathrm{F}_{\tau}\right)$ were calculated for binary mixtures of different concentrations $(0,25,50,75$ and $100 \mathrm{vol} . \%$ ) of MA with 2-Alkoxyethanols (2-methoxyethanol, 2-ethoxyethanol and 2-butoxyethanol) using time domain reflectometry. The operating frequency range is from $10 \mathrm{MHz}$ to $20 \mathrm{GHz}$ at temperature $308.15 \mathrm{~K}$ and was reported in Table 3 . 
The frequency dependent values of permittivity $\left(\varepsilon^{\prime}\right)$ and dielectric loss ( $\left.\varepsilon^{\prime \prime}\right)$ of Methyl acetate (MA) with 2-Alkoxyethanols mixtures at $308.15 \mathrm{~K}$ are shown in Fig. 1 and Fig. 2 . The static dielectric constant $\left(\varepsilon_{\mathrm{o}}\right)$, static permittivity at high frequency $\left(\varepsilon_{\infty}\right)$ and relaxation time $(\tau)$ were obtained by using the non-linear least-square fit method [20]. The general form of the relaxation model is given by Havriliak-Negami equation [21].

$$
\varepsilon^{*}(\omega)=\varepsilon_{\infty}+\frac{\left(\varepsilon_{0}-\varepsilon_{\infty}\right)}{\left[1+(j \omega \tau)^{(1-\alpha)}\right]^{\beta}}
$$

where $\varepsilon^{*}(\omega)$ is the complex reflection coefficient, $\left(\varepsilon_{0}\right)$ is the static dielectric constant, $\left(\varepsilon_{\infty}\right)$ is the static permittivity at high frequency, $(\tau)$ is the relaxation time, $\alpha$ and $\beta$ are empirical parameters for the distribution of relaxation times with values between 0 and 1. The Havriliak-Negami equation includes three relaxation modes as limiting forms. The Debye mode $(\alpha=0$ and $\beta=1)$ implies a single relaxation time while Cole-Cole $(\alpha=1$ and $\beta=1)$ and Cole Davidson $(\alpha=0$ and $\beta=1)$ both suggest a distribution of relaxation times. But the polar-polar binary mixtures volume percentage of all concentration of Methyl acetate with 2-Alkoxyethanols could fit Debye type dispersion. Therefore, here $(\alpha=0$ and $\beta=1)$ and experimental values of $\varepsilon^{*}(\omega)$ were fitted to the Debye equation as,

$$
\varepsilon^{*}(\omega)=\varepsilon_{\infty}+\frac{\left(\varepsilon_{0}-\varepsilon_{\infty}\right)}{[1+(j \omega \tau)]^{\beta}}
$$

The values of $\left(\varepsilon_{0}\right),(\tau)$ and $\left(\varepsilon_{\infty}\right)$ are fitting parameters. The parameters like effective Kirkwood correlation factor $\left(g^{\text {eff }}\right)$, corrective Kirkwood correlation factor $\left(g_{f}\right)$, Bruggeman factor $\left(f_{\mathrm{B}}\right)$, excess dielectric constant $\left(\varepsilon^{\mathrm{E}}\right)$ and excess inverse relaxation time $(1 / \tau)^{\mathrm{E}}$ values of MA with 2-Alkoxyethanol binary mixtures were reported in Table 4. The excess Helmholtz free energy values are also reported in Table 5 with their volume fractions of methyl acetate.

\section{DISCUSSION}

The binary liquid systems taken for the study are

1) Methyl acetate +2 -methoxyethanol

2) Methyl acetate +2 -ethoxyethanol

3) Methyl acetate +2 -butoxyethanol
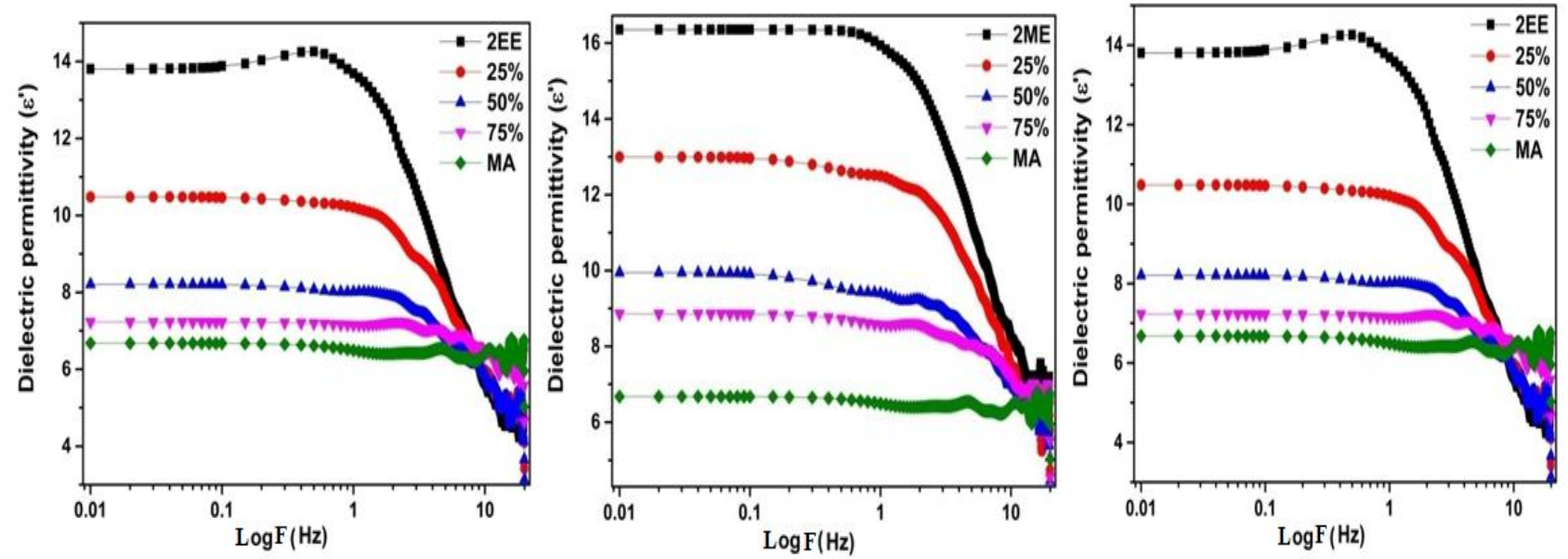

Fig. 1: Dielectric permittivity spectra vs. $\log \mathrm{F}\left(\mathrm{H}_{\mathrm{Z}}\right)$ of Methyl acetate (MA) with 2-methoxyethanol (2-ME), 2-ethoxyethanol (2-EE) and 2-butoxyethanol (2-BE). 

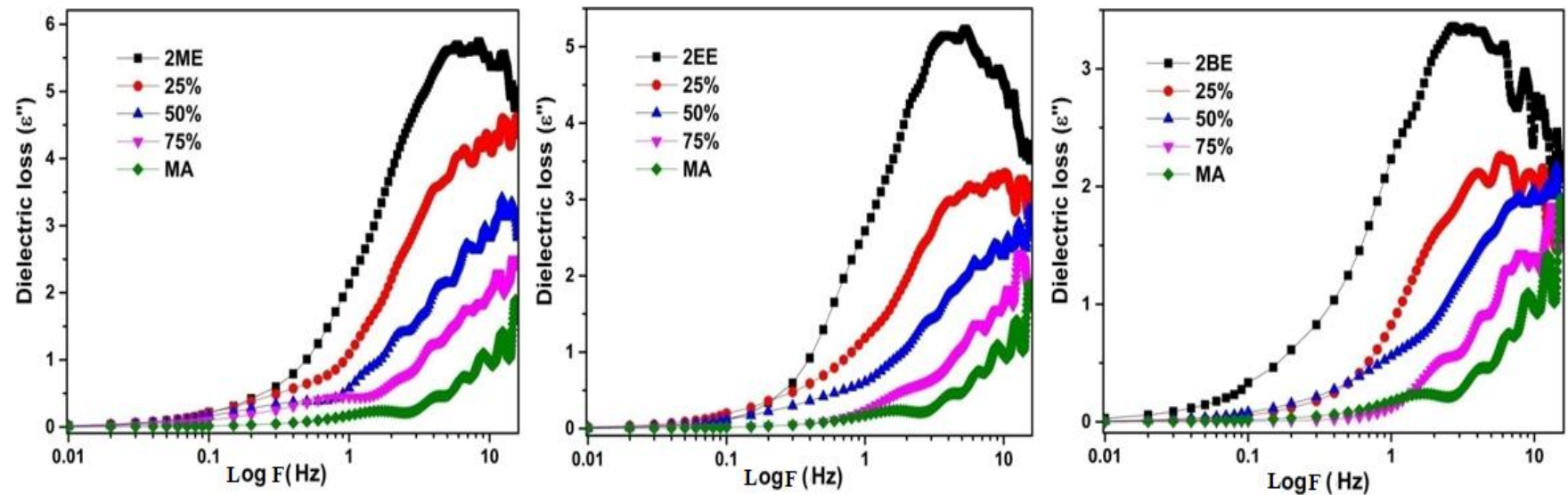

Fig. 2: Dielectric loss spectra vs. Log F $\left(\mathrm{H}_{\mathrm{Z}}\right)$ of Methyl acetate (MA) with 2-methoxyethanol (2-ME), 2-ethoxyethanol (2-EE) and 2-butoxyethanol (2-BE).

Table 3: Values of static dielectric constant $\left(\varepsilon_{0}\right)$, dielectric constant at an optical frequency $\left(\varepsilon_{\infty}\right)$, relaxation time $(\tau)$ and activation energy of relaxation time $\left(\Delta \mathrm{F}_{\tau}\right)$ with volume fraction of Methyl acetate $\left(\varphi_{2}\right)$

\begin{tabular}{|c|c|c|c|c|}
\hline $\boldsymbol{\varphi}_{\mathbf{2}}$ & $\boldsymbol{\varepsilon}_{\mathbf{0}}$ & $\boldsymbol{\varepsilon}_{\infty}$ & $\begin{array}{c}\boldsymbol{\tau} \\
\mathbf{p s}\end{array}$ & $\mathbf{F}_{\boldsymbol{\tau}}$ \\
\hline \multicolumn{5}{|c|}{ System-I: Methyl acetate + 2-methoxyethanol } \\
\hline 0 & 16.06 & 1.9488 & 29.20 & 125.5138 \\
\hline 0.25 & 11.98 & 1.9516 & 21.59 & 124.7401 \\
\hline 0.50 & 9.25 & 1.9530 & 14.30 & 123.6845 \\
\hline 0.75 & 8.08 & 1.9155 & 10.34 & 122.8532 \\
\hline 1.0 & 6.19 & 1.8360 & 7.99 & 122.1929 \\
\hline \multicolumn{5}{|c|}{ System-II Methyl acetate + 2-ethoxyethanol } \\
\hline 0 & 15.46 & 1.9656 & 36.46 & 126.0828 \\
\hline 0.25 & 9.74 & 1.9605 & 23.5 & 124.9573 \\
\hline 0.50 & 7.61 & 1.9516 & 15.7 & 123.9238 \\
\hline 0.75 & 6.78 & 1.9238 & 9.97 & 122.7599 \\
\hline 1.0 & 6.19 & 1.8360 & 7.99 & 122.1929 \\
\hline \multicolumn{5}{|c|}{ System-III: Methyl acetate + 2-butoxyethanol } \\
\hline 0 & 9.21 & 1.9966 & 51.93 & 126.9890 \\
\hline 0.25 & 8.47 & 1.9952 & 30.52 & 125.6271 \\
\hline 0.50 & 7.06 & 1.9980 & 15.94 & 123.9627 \\
\hline 0.75 & 6.95 & 1.9572 & 10.29 & 122.8414 \\
\hline 1.0 & 6.19 & 1.8360 & 7.99 & 122.1929 \\
\hline \multicolumn{5}{|c|}{}
\end{tabular}

Table 4: Values of kirkood correlation factors $\left(g^{\text {eff }}, g_{f}\right)$, Bruggeman factor $\left(f_{B}\right)$, Excess dielectric constant $\left(\varepsilon^{\mathrm{E}}\right)$ and excess inverse relaxation time $(1 / \tau)^{\mathrm{E}}$ with volume fraction of Methyl acetate $\left(\varphi_{2}\right)$

\begin{tabular}{|c|c|c|c|c|c|}
\hline $\mathbf{p}_{\mathbf{2}}$ & $\mathbf{g}^{\text {eff }}$ & $\mathbf{g}_{\mathbf{f}}$ & $\mathbf{f}_{\mathbf{B}}$ & $\mathbf{\varepsilon}^{\mathbf{E}}$ & $\begin{array}{c}(\mathbf{1} / \boldsymbol{\tau})^{\mathbf{E}} \\
\text { Ps }\end{array}$ \\
\hline \multicolumn{7}{|c|}{ System-I: Methyl acetate + 2-methoxyethanol } \\
\hline 0 & 1.3954 & 1.0000 & 1.0000 & 0.0000 & 0.0000 \\
\hline 0.25 & 1.1463 & 0.8629 & 0.6468 & -1.6435 & -0.0107 \\
\hline 0.50 & 0.9854 & 0.7945 & 0.3726 & -1.9356 & -0.0098 \\
\hline 0.75 & 1.0177 & 0.9090 & 0.2408 & -0.6287 & -0.0057 \\
\hline 1.0 & 0.9439 & 1.0000 & 0.0000 & 0.0000 & 0.0000 \\
\hline \multicolumn{7}{|c|}{ System-II Methyl acetate + 2-ethoxyethanol } \\
\hline 0 & 2.1000 & 1.0000 & 1.0000 & 0.0000 & 0.0000 \\
\hline
\end{tabular}




\begin{tabular}{|c|c|c|c|c|c|}
\hline 0.25 & 1.3124 & 0.7095 & 0.4467 & -3.4298 & -0.0093 \\
\hline 0.50 & 1.0291 & 0.6529 & 0.1940 & -3.2658 & -0.0126 \\
\hline 0.75 & 0.9513 & 0.7457 & 0.0838 & -1.7829 & -0.0004 \\
\hline 1.0 & 0.9439 & 1.0000 & 0.0000 & 0.0000 & 0.0000 \\
\hline \multicolumn{7}{|c|}{ System-III: Methyl acetate + 2-butoxyethanol } \\
\hline 0 & 1.5633 & 1.0000 & 1.0000 & 0.0000 & 0.0000 \\
\hline 0.25 & 1.3735 & 0.9850 & 0.7763 & -0.0237 & -0.0130 \\
\hline 0.50 & 1.0630 & 0.8604 & 0.3148 & -0.7217 & -0.0095 \\
\hline 0.75 & 1.0392 & 0.9573 & 0.2764 & -0.0760 & -0.0015 \\
\hline 1.0 & 0.9439 & 1.0000 & 0.0000 & 0.0000 & 0.0000 \\
\hline
\end{tabular}

\subsection{Dielectric permittivity $\left(\varepsilon^{\prime}\right)$}

The complex permittivity spectra of two pure liquids as well as the three binary mixtures of Methyl acetate (MA) with 2methoxyethanol (2-ME), 2-ethoxyethanol (2-EE) and 2-butoxyethanol (2-BE) are shown in Fig 1. In the case of MA with 2Alkoxyethanols systems, a graph is drawn between dielectric permittivity $\left(\varepsilon^{\prime}\right)$ on the $\mathrm{Y}$-axis and $\log \mathrm{F}$ on the $\mathrm{X}$-axis. From the graph it is inferred that the dielectric permittivity $\left(\varepsilon^{\prime}\right)$ is comparatively low for MA and is high for 2-Alkoxyethanols. As the MA concentration increases, the dielectric permittivity $\left(\varepsilon^{\prime}\right)$ values gets decreases. In other words as the concentration of $2-$ Alkoxyethanols increases the dielectric permittivity $\left(\varepsilon^{\prime}\right)$ values gets increases. Hence $\left(\varepsilon^{\prime}\right)$ values are directly proportional to the 2-Alkoxyethanols concentrations and inversely proportional to the MA concentration.

\subsection{Dielectric loss $\left(\varepsilon^{\prime \prime}\right)$}

A graph is drawn between dielectric loss $(\varepsilon ")$ on $\mathrm{Y}$-axis and $\log \mathrm{F}$ on $\mathrm{X}$-axis and is shown in fig. 2. The position of the peak of the curves shifts towards higher side (right) of Log F. As the Log F increases, the dielectric loss ( $\left.\varepsilon^{\prime \prime}\right)$ also gets increases. It is found that when comparing all the three alcohols with Methyl acetate, the dielectric loss is in the order of 2-ME > 2-EE > 2BE.

Table 5: Values of excess Helmholtz free energy $\left(\Delta \mathrm{F}^{\mathrm{E}}\right)$ and its components with volume fraction of Methyl acetate $\left(\varphi_{2}\right)$

\begin{tabular}{|c|c|c|c|c|}
\hline $\boldsymbol{\varphi}_{\mathbf{2}}$ & $\begin{array}{c}\Delta \mathbf{F}_{\mathbf{~} \mathbf{r}}{ }^{\mathbf{E}} \\
\mathbf{J} / \mathbf{m o l}\end{array}$ & $\begin{array}{c}\Delta \mathbf{F}_{\text {rr }}{ }^{\mathbf{E}} \\
\mathbf{J} / \mathbf{m o l}\end{array}$ & $\begin{array}{c}\Delta \mathbf{F}_{\mathbf{1 2}}{ }^{\mathrm{E}} \\
\mathbf{J} / \mathbf{m o l}\end{array}$ & $\begin{array}{c}\Delta \mathbf{F}^{\mathrm{E}} \\
\mathbf{J} / \mathbf{m o l}\end{array}$ \\
\hline \multicolumn{5}{|c|}{ System-I: Methyl acetate + 2-methoxyethanol } \\
\hline 0 & 0.0000 & 0.0000 & 0.0000 & 0.0000 \\
\hline 0.25 & 83.3704 & 57.9874 & -11.0806 & 130.2772 \\
\hline 0.50 & 124.9438 & 57.1200 & 0.0143 & 182.0780 \\
\hline 0.75 & 27.3371 & 23.8875 & 0.8026 & 52.0271 \\
\hline 1.0 & 0.0000 & 0.0000 & 0.0000 & 0.0000 \\
\hline \multicolumn{5}{|c|}{ System-II Methyl acetate + 2-ethoxyethanol } \\
\hline 0 & 0.0000 & 0.0000 & 0.0000 & 0.0000 \\
\hline 0.25 & 133.4999 & 176.8102 & -8.8210 & 301.4891 \\
\hline 0.50 & 163.6883 & 135.9551 & 1.5191 & 301.1625 \\
\hline 0.75 & 93.9439 & 43.2267 & -3.6792 & 133.4914 \\
\hline 1.0 & 0.0000 & 0.0000 & 0.0000 & 0.0000 \\
\hline \multicolumn{5}{|c|}{ System-III: Methyl acetate + 2-butoxyethanol } \\
\hline 0 & 0.0000 & 0.0000 & 0.0000 & 0.0000 \\
\hline 0.25 & -20.3300 & 16.7025 & -16.7606 & -20.3881 \\
\hline 0.50 & 33.5534 & 25.5652 & 0.2404 & 59.3590 \\
\hline 0.75 & -23.5248 & 9.3315 & 0.2864 & -13.9070 \\
\hline 1.0 & 0.0000 & 0.0000 & 0.0000 & 0.0000 \\
\hline \multicolumn{7}{|c|}{} \\
\hline
\end{tabular}

\subsection{Static dielectric constant $\left(\varepsilon_{0}\right)$}

The static dielectric constant values of Methyl acetate (MA) is 6.19, 2-methoxyethanol (2-ME) is 16.06, 2-ethoxyethanol (2-EE) is 15.46 and 2-butoxyethanol (2-BE) is 9.21. In the case of MA with 2-ME, 2-EE and 
2-BE systems, as the volume percent of MA increases the static dielectric constant $\left(\varepsilon_{0}\right)$ values gets decreases and approaching towards the 2-Alkoxyethanols dielectric constant values.

\subsection{Dielectric constant at an optical frequency $\left(\varepsilon_{\infty}\right)$}

As the volume percent of the Methyl acetate molecule increases, the dielectric constant at an optical frequency $\left(\varepsilon_{\infty}\right)$ values gets increases at the initial concentration and then decreases at higher concentration of Methyl acetate (MA) with 2-ME, 2-EE and the 2-BE systems.

\subsection{Relaxation time $(\tau)$}

The relaxation time depends on the nature of participating functional groups and volume of molecule. Functional groups are those able to form the hydrogen bonding which have a strong influence on relaxation times. In the pure state the experimental relaxation time values of Methyl acetate is 7.99 ps, 2-methoxyethanol is 29.20 ps, 2-ethoxyethanol is $36.46 \mathrm{ps}$ and 2-butoxyethanol is $51.93 \mathrm{ps}$ at $308.15 \mathrm{~K}$. The 2-methoxyethanol relaxation time is low when compared to 2-ethoxyethanol and 2-butoxyethanol. The relaxation time value is high for 2-butoxy ethanol due to the higher chain length of alkyl group.

Alcohols play a vital role in the structural dynamics and relaxation mechanism of the individual components. This is due to the formation of intra molecular hydrogen bonding between one alcohol molecule and another alcohol molecule ( $\mathrm{R}-\mathrm{O}-$ $\mathrm{H} \cdots \mathrm{OH}-\mathrm{R}$ ) and leads to the formation of self associated groups. There is an increment in the number of self associated groups which causes the alcohol molecules to absorb more electromagnetic energy. Due to this reason molecule rotate slowly leading to higher relaxation times. Further, it is observed that the relaxation times of pure 2-BE is greater than that of pure 2-ME, 2EE due to larger effective radius of the rotating unit [22].

From the relaxation time values of three binary liquid systems, it is observed that the relaxation time is higher for $\mathrm{MA}+2-\mathrm{BE}$ system. The relaxation time is in the order of $\mathrm{MA}+2-\mathrm{BE}>\mathrm{MA}+2-\mathrm{EE}>\mathrm{MA}+2-\mathrm{ME}$.

The dielectric parameters like the static dielectric constant $\left(\varepsilon_{0}\right)$, dielectric constant at an optical frequency $\left(\varepsilon_{\infty}\right)$ and relaxation time $(\tau)$ values calculated are found to be non linear behaviour and can be attributed to the appearance of aggregates in solutions.

\subsection{Free energy of activation for relaxation time $\left(\Delta F_{\tau}\right)$}

$$
\Delta \mathrm{F}_{\tau}=\text { RT } 2.303 \log _{10}\left[\frac{\tau_{0} \mathbf{K T}}{h}\right] \ldots \ldots \ldots \text { (3) }
$$

$\mathrm{T}$ is absolute temperature, $\mathrm{K}-$ Boltzman constant, $\mathrm{h}$ is a Plank's constant, $\tau_{\mathrm{o}}$ is relaxation time, $\Delta \mathrm{F}_{\tau}$ is Free energy activation for relaxation time. The study of thermodynamic properties like free energy of activation for dielectric relaxation $\Delta \mathrm{F}_{\tau}$ for polar compounds may be useful in accordance with the states of dipoles under the influence of applied field. The measurement of free energy of activation for dielectric relaxation $\left(\Delta \mathrm{F}_{\tau}\right)$ is calculated for all the systems studied. It is clear from the data that the dielectric relaxation time $\left(\Delta \mathrm{F}_{\tau}\right)$ involves rotational motion only and not due to translational motion, which is pertaining to the free energy of activation for viscous flow $\left(\Delta \mathrm{F}_{\eta}\right)$. Free energy of activation for relaxation time is in the order of $\mathrm{MA}+2-\mathrm{BE}>\mathrm{MA}+2-\mathrm{EE}>\mathrm{MA}+2-\mathrm{ME}$. The values are given in the Table 3.

\subsection{Effective Kirkwood correlation factor $\left(\mathrm{g}^{\text {eff }}\right)$}

The structural information about the molecules of the liquids by dielectric relaxation parameter can be obtained by Kirkwood correlation factor ' $\mathrm{g}$ ' [23]. The Kirkwood correlation factor provides useful information regarding the orientation of dipoles in polar liquids. The ' $\mathrm{g}$ ' factor for the pure liquid may be obtained from the expression,

$$
\frac{4 \pi N_{A} \mu^{2} \rho}{9 k T M} g=\frac{\left(\varepsilon_{0}-\varepsilon_{\infty}\right)\left(2 \varepsilon_{0}+\varepsilon_{\infty}\right)}{\varepsilon_{0}\left(\varepsilon_{\infty}+2\right)^{2}} .
$$

where $\mathrm{N}_{\mathrm{A}}$ is Avogadro's number, $\mu$ is the dipole moment in the gas phase, $\rho$ is the density, $\mathrm{K}$ is the Boltzmann constant, $\mathrm{T}$ is the temperature in Kelvin, $\mathrm{M}$ is the molecular weight, $\varepsilon_{0}$ is the static dielectric constant and $\varepsilon_{\infty}$ is the dielectric constant at optical frequency which is the square of the refractive index. Modified forms of this equation have been used to 
study the orientation of electric dipoles in binary mixture of Methyl acetate with 2-Alkoxyethanols. Equation (4) is modified and is called as $\left(\mathrm{g}^{\text {eff }}\right)$ the effective Kirkwood correlation factor [24],

$$
\frac{4 \pi N_{A}}{9 k T}\left(\frac{\mu_{1}^{2} \rho_{1}}{M_{1}} \phi_{1}+\frac{\mu_{2}^{2} \rho_{2}}{M_{2}} \phi_{2}\right) g^{e f f}=\frac{\left(\varepsilon_{0 m}-\varepsilon_{\infty m}\right)\left(2 \varepsilon_{0 m}+\varepsilon_{\infty m}\right)}{\varepsilon_{0 m}\left(\varepsilon_{\infty m}+2\right)^{2}}
$$

The effective Kirkwood correlation factor $\left(g^{\text {eff }}\right)$ calculated using equation $(5)$ is given in Table 4. If the ( $g^{\text {eff }}$ ) values are greater than unity which indicates the parallel orientation of dipoles and if less than unity it indicates the anti-parallel orientation of dipoles. In the pure state the ( $\left.\mathrm{g}^{\mathrm{eff}}\right)$ values of 2-methoxyethanol is (1.3954), 2-ethoxyethanol is (2.1000) and 2-butoxyethanol is (1.5633) are greater than unity having parallel orientation of electric dipoles. The $\left(\mathrm{g}^{\text {eff }}\right)$ values calculated for pure Methyl acetate is less than unity, indicating anti-parallel orientation of dipoles or no dipole correlation of electric dipoles. As the volume percentage of solute increases, the $\left(g^{\text {eff }}\right)$ values get decreases for all the systems studied.

\subsection{Corrective Kirkwood correlation factor $\left(\mathrm{g}_{\mathbf{f}}\right)$}

The structural information on the interacting species is obtained by another correlation factor named as corrective Kirkwood correlation factor $\left(\mathrm{g}_{\mathrm{f}}\right)$. It is a dielectric parameter which supplies essential information regarding interaction of the participating molecules in the mixture. For an ideal mixture, $\left(g_{f}\right)$ must be unity and the deviation of $\left(g_{f}\right)$ from unity indicates the magnitude of interaction between the compounds i.e., If there is a greater deviation from unity means a larger the strength of interactions [25].

$$
\frac{4 \pi N_{A}}{9 k T}\left(\frac{\mu_{1}^{2} \rho_{1} g_{1}}{M_{1}} \phi_{1}+\frac{\mu_{2}^{2} \rho_{2} g_{2}}{M_{2}} \phi_{2}\right) g_{f}=\frac{\left(\varepsilon_{0 m}-\varepsilon_{\infty m}\right)\left(2 \varepsilon_{0 m}+\varepsilon_{\infty m}\right)}{\varepsilon_{0 m}\left(\varepsilon_{\infty m}+2\right)^{2}} \ldots \ldots \ldots . .(6)
$$

where $\mathrm{N}_{\mathrm{A}}$ is Avogadro's number, $\mu$ is the dipole moment in the gas phase, $\rho$ is the density, $\mathrm{K}$ is the Boltzmann constant, $\mathrm{T}$ is the temperature in Kelvin, $\mathrm{M}$ is the molecular weight, $\varepsilon_{0 \mathrm{~m}}$ is the static dielectric constant of mixture and ( $\left.\varepsilon_{\infty}\right)$ is the dielectric constant at optical frequency which is the square of the refractive index of the mixture. The corrective Kirkwood correlation factor $\left(\mathrm{g}_{\mathrm{f}}\right)$ was calculated by using equation (6).

If $\left(g_{f}\right)$ values will remain close to unity then there is no interaction between the molecules. In the present study, the values of $\left(g_{f}\right)$ are close to unity for all the systems. But $\left(g_{f}\right)$ values are found to be deviate more from unity for MA $+2-E E$ system. This indicates that effective dipoles in the mixture are greater than the average of those in the pure compounds. The values of $\left(g_{f}\right)$ are found to be depending more on the concentration than the temperature, as reported by Balamurugan et al., [26].

\subsection{Bruggeman factor $\left(f_{B}\right)$}

The information about the solute-solvent interaction is given by the Bruggeman factor $\left(\mathrm{f}_{\mathrm{B}}\right)$. The effective volume of the solute gets modified by solute - solvent interactions and is best illustrated by the non - linearity of the Bruggeman formula [27].

$$
f_{B}=\left(\frac{\left(\varepsilon_{0 m}-\varepsilon_{02}\right)}{\left(\varepsilon_{01}-\varepsilon_{02}\right)}\right)\left(\frac{\varepsilon_{01}}{\varepsilon_{0 m}}\right)^{1 / 3}=\left(1-\phi_{2}\right)
$$

According to equation (7), a non linear relationship is expected between $\left(f_{B}\right)$ and Volume fraction of Methyl acetate.

The non linear relation of $\left(\mathrm{f}_{\mathrm{B}}\right)$ of Methyl acetate with 2-ME, 2-EE and 2-BE suggest that there is an intermolecular interaction between the mixed components. A graph is drawn between Bruggeman factor $\left(f_{B}\right)$ and volume fraction $\left(\varphi_{2}\right)$ of Methyl acetate which is shown in Fig. 3. 


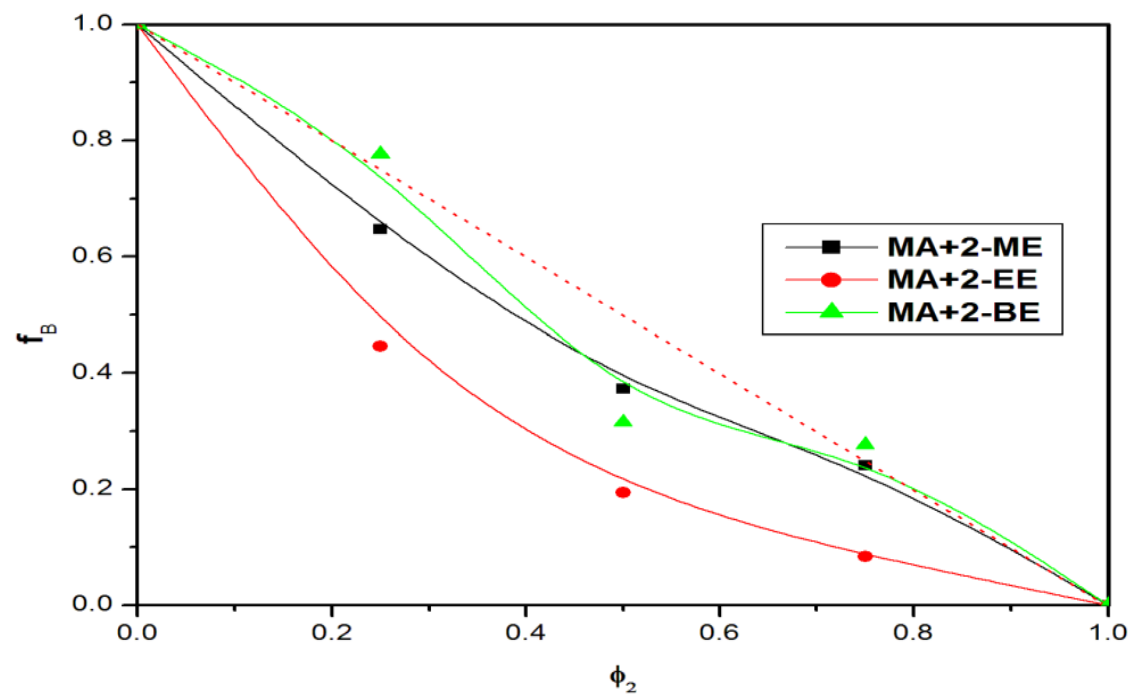

Fig. 3. Bruggeman factor ( $\left.f_{B}\right)$ vs. volume fraction of Methyl acetate $\left(\varphi_{2}\right)$

In our studied systems, it is observed that there are deviations from the ideal linearity of Bruggeman line (dotted line). It means that there exists some sort of interactions prevailing among the participating liquids. The non linearity of the ( $\mathrm{f}_{\mathrm{B}}$ ) behavior indicates that the hetero interaction, which may be due to hydrogen bonding of the $-\mathrm{OH}$ group of alcohol with $\mathrm{C}=\mathrm{O}$ group of Ester [28; 26].

\subsection{Excess dielectric constant $\left(\varepsilon^{\mathrm{E}}\right)$}

The excess permittivity is defined as [29],

$$
\varepsilon^{E}=\left(\varepsilon_{0}-\varepsilon_{\infty}\right)_{m}-\left\{\left(\varepsilon_{0}-\varepsilon_{\infty}\right)_{1} \phi_{1}+\left(\varepsilon_{0}-\varepsilon_{\infty}\right)_{2} \phi_{2}\right\}
$$

Where $\phi_{1}$ and $\phi_{2}$ represents the volume fractions of liquid 1 (2-Alkoxyethanols) and liquid 2 (Methyl acetate). The excess dielectric constant $\left(\varepsilon^{\mathrm{E}}\right)$ provides information about the formation of multimers in the mixture as follows:

1. If $\varepsilon^{\mathrm{E}}=0$ which indicates that there is no interaction between the components in the mixture.

2. If $\varepsilon^{\mathrm{E}}<0$ which reveals that components in the mixture may form closed multimers leading to the less effective dipoles due to the interaction between the components in such a way that the effective dipole moment gets reduced.

3. If $\varepsilon^{\mathrm{E}}>0$ which denotes that components in the mixture interact in such a way that the effective dipole moment is increased. There is a probability for the formation of linear multimers. In an ideal mixture of polar liquids if the molecules are interacting, a non linear variation in dielectric constant and relaxation time occurs. This confirms that the intermolecular association is taking place in these systems.

The values of excess dielectric constant $\left(\varepsilon^{\mathrm{E}}\right)$ of Methyl acetate with 2-alkoxyethanols (2-methoxyethanol, 2-ethoxyethanol and 2-butoxyethanol) are listed in Table 4. In an ideal mixture of polar liquids, if the molecules are interacting, a non linear variation in excess dielectric constant $\left(\varepsilon^{\mathrm{E}}\right)$ occurs. This confirms that the intermolecular association is taking place in the systems.

In the present study excess dielectric constant $\left(\varepsilon^{\mathrm{E}}\right)$ values are negative for all the systems selected (i.e) Methyl acetate with 2-ME, $2-\mathrm{EE}$ and 2-BE systems. The negative value of $\left(\varepsilon^{\mathrm{E}}\right)$ indicates that molecules of the mixtures may form closed multimers structures via hydrogen bonding in such a way that the effective dipoles get reduced. The excess property related to static dielectric constant and relaxation time provides significant information regarding interaction between the polar-polar liquid mixtures [30, 31].

\subsection{Excess inverse relaxation time $(1 / \tau)^{E}$}

The excess inverse relaxation time is defined as,

$$
\left(\frac{1}{\tau}\right)^{E}=\left(\frac{1}{\tau}\right)_{m}-\left\{\left(\frac{1}{\tau}\right)_{1} \phi_{1}+\left(\frac{1}{\tau}\right)_{2} \phi_{2}\right\} \ldots \ldots \ldots .(9)
$$


where $(1 / \tau)^{\mathrm{E}}$ is excess inverse relaxation time which represents the average broadening of dielectric spectra. The inverse relaxation time analogy is taken from spectral line broadening in the resonant spectroscopy [32]. The information regarding the dynamic of the molecules of liquids 1 and 2 is as follows:

(i) If $(1 / \tau)^{\mathrm{E}}=0$ : then there is no change in the dynamics of liquids 1 and 2 interaction.

(ii) If $(1 / \tau)^{\mathrm{E}}<0$ : then the liquids 1 and 2 interaction produces a field such that the effective dipoles rotate slowly.

(iii) If $(1 / \tau)^{\mathrm{E}}>0$ : then the liquids 1 and 2 interaction produces a field such that the effective dipoles rotate fastly i.e. the fields will co-operate in the rotation of dipoles.

The excess inverse relaxation time $(1 / \tau)^{\mathrm{E}}$ is calculated for Methyl acetate with 2-Alkoxyethanols systems and is shown in Table 4 . From the data it reveals that all the $(1 / \tau)^{\mathrm{E}}$ values are negative. It means that the interaction between the molecules of liquid 1 and liquid 2 produces a field such that the effective dipoles rotate slowly due to the formation of $\mathrm{H}-$ bonded structures [25, 26].

\subsection{Excess Helmholtz free energy $\left(\Delta \mathbf{F}^{\mathrm{E}}\right)$}

The study of Excess Helmholtz free energy gives information on the interaction between the components in the mixture through the breaking mechanism of the $\mathrm{H}$-bonds. The excess free energy due to mixing is given as [33];

$$
\left(\Delta \mathrm{F}^{\mathrm{E}}\right)=\left(\Delta \mathrm{F}_{0 \mathrm{r}}^{\mathrm{E}}\right)+\left(\Delta \mathrm{F}_{\mathrm{rr}}^{\mathrm{E}}\right)+\left(\Delta \mathrm{F}_{12}^{\mathrm{E}}\right)
$$

where, $\left(\Delta \mathrm{F}_{0 \mathrm{r}}^{\mathrm{E}}\right)$ represents the excess dipolar energy due to long range electrostatic interaction. $\left(\Delta \mathrm{F}_{\text {rr }} \mathrm{E}\right)$ represents the excess dipolar energy due to short range interaction between identical molecules and $\left(\Delta \mathrm{F}_{12}{ }^{\mathrm{E}}\right)$ represents the excess free energy due to short range interaction between dissimilar molecules. The above terms are given in detail in equation (11):

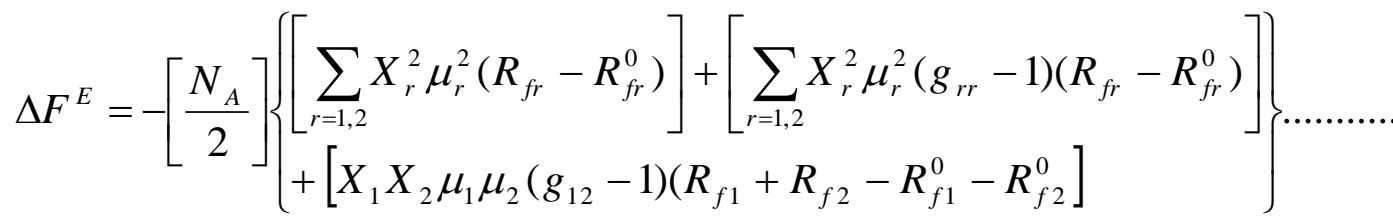

$$
\begin{aligned}
& R_{f r}^{0}=\left(\frac{8 \pi N_{A}}{9 V_{r}}\right) \frac{\left(\varepsilon_{r}-1\right)\left(\varepsilon_{\infty r}+2\right)}{\left(2 \varepsilon_{r}+\varepsilon_{\infty r}\right)} \\
& R_{f r}=\left(\frac{8 \pi N_{A}}{9 V_{r}}\right) \frac{\left(\varepsilon_{m}-1\right)\left(\varepsilon_{\infty r}+2\right)}{\left(2 \varepsilon_{m}+\varepsilon_{\infty r}\right)}
\end{aligned}
$$

$\mathrm{V}_{\mathrm{r}}$ is the molar volume of the components. $\left(\varepsilon_{\mathrm{r}}\right)$ and $\left(\varepsilon_{\infty \mathrm{r}}\right)$ are the static dielectric constant and static dielectric constant at optical frequencies, of the pure liquids, respectively.

The long range and short range interaction between dipoles can be studied from the thermodynamic parameter, excess Helmholtz free energy $\left(\Delta \mathrm{F}^{\mathrm{E}}\right)$. The different components of $\Delta \mathrm{F}^{\mathrm{E}}$ such as $\Delta \mathrm{F}_{0 \mathrm{r}}{ }^{\mathrm{E}}, \Delta \mathrm{F}_{\mathrm{rr}}{ }^{\mathrm{E}}$ and $\Delta \mathrm{F}_{12}{ }^{\mathrm{E}}$ are given in Table 5. The first term $\Delta \mathrm{F}_{0 \mathrm{r}}{ }^{\mathrm{E}}$ represents the excess dipolar energy due to the long range electrostatic interaction between similar molecules. The second term $\Delta \mathrm{F}_{\text {rr }}{ }^{\mathrm{E}}$ represents the excess dipolar energy due to the short range interaction between the similar molecules. The third term $\Delta \mathrm{F}_{12}{ }^{\mathrm{E}}$ represents the excess free energy due to short range interaction between dissimilar molecules. The long range interaction between the dipoles in the mixture can be identified from the values of $\Delta \mathrm{F}_{0 \mathrm{r}}{ }^{\mathrm{E}}[34]$.

In the present study, $\mathrm{MA}+2-\mathrm{ME}$ and $\mathrm{MA}+2-\mathrm{EE}$ systems have positive values of $\Delta \mathrm{F}_{0 \mathrm{r}}^{\mathrm{E}}$ which indicates the existence of attractive forces between the dipoles. Where as in the $\mathrm{MA}+2-\mathrm{BE}$ system $\Delta \mathrm{F}_{0 \mathrm{r}}{ }^{\mathrm{E}}$ have negative values which indicates the repulsive forces between the dipoles.

The second term $\left(\Delta \mathrm{F}_{\mathrm{rr}}{ }^{\mathrm{E}}\right)$ gives the excess free energy due to short range interaction between the like molecules. (i.e) $\left(\Delta \mathrm{F}_{\mathrm{rr}}{ }^{\mathrm{E}}\right)$ indicates rupture of $\mathrm{H}$ - bonds between the acid (ester) molecules formed by short range interaction. As the concentration of the solute molecules increases, the $\left(\Delta \mathrm{F}_{\mathrm{rr}}{ }^{\mathrm{E}}\right)$ values are positive and indicate the strong short range interaction through $\mathrm{H}-$ bonding. The $\left(\Delta \mathrm{F}_{\mathrm{rr}}{ }^{\mathrm{E}}\right)$ values gradually increases first and attains maximum at equimolar concentrations and then gradually decreases in all the studied systems. The magnitude of $\Delta \mathrm{F}_{12}{ }^{\mathrm{E}}$ gives information on the strength of interactions between unlike molecules. The values of $\Delta \mathrm{F}_{12}{ }^{\mathrm{E}}$ calculated in the systems of Methyl acetate with 2-Alkoxyethanols are both the positive and negative values, which indicate that the hetero interaction between the compounds which are varying with concentration and temperature. 
The excess Helmholtz free energy values are completely positive for MA+2-ME and MA+2-EE system. Whereas it is found to be positive and negative for MA+2-BE system. Which indicates the formation of $\beta$-clusters to $\alpha$-clusters (i.e) anti-parallel to parallel alignment of dipoles takes place $[25,35]$. From the results of the studied systems, intermolecular interaction depends on the molecular size, volume and the functional group.

\section{FTIR STUDIES}

The FTIR spectra of Methyl acetate with 2-Alkoxyethanols are shown in Figure 4. The Table 6 shows the O-H stretching vibrations are observed for 2-methoxyethanol at $\left(3411 \mathrm{~cm}^{-1}\right)$, for 2-ethoxyethanol at $\left(3420 \mathrm{~cm}^{-1}\right)$ and 2-butoxyethanol at $(3422$ $\left.\mathrm{cm}^{-1}\right)$, respectively. The transmittance spectra of broad band appeared for MA+2-ME system at $\left(3412 \mathrm{~cm}^{-1}\right)$, for MA+2-EE system at $\left(3422 \mathrm{~cm}^{-1}\right)$ and for MA+2-BE system at $\left(3425 \mathrm{~cm}^{-1}\right)$, which is attributed to the stretching frequency of O-H bond in binary system. The $\mathrm{CH}_{2}$ asymmetric stretching were observed at $2932 \mathrm{~cm}^{-1}, 2935 \mathrm{~cm}^{-1}, 2935 \mathrm{~cm}^{-1}$ for MA+2-ME, MA+2-EE and $\mathrm{MA}+2-\mathrm{BE}$ systems respectively. The $\mathrm{C}=\mathrm{O}$ stretching for pure $\mathrm{MA}$ is observed at frequency $1777 \mathrm{~cm}^{-1}$. The $\mathrm{C}=\mathrm{O}$ vibrations are observed at $1778 \mathrm{~cm}^{-1}$ for $\mathrm{MA}+2-\mathrm{ME}, \mathrm{MA}+2-\mathrm{EE}$ and $\mathrm{MA}+2-\mathrm{BE}$ systems respectively. These vibrations are nearly coinciding with literature value [36]. We also observed the $\mathrm{O}-\mathrm{H}$ and $\mathrm{C}=\mathrm{O}$ shifted to the higher frequency with increase in mole fraction of Methyl acetate with 2-Alkoxyethanols binary mixtures. The formation of complexes is may be due to the hydrogen bonding between the oxygen of carbonyl group $(\mathrm{C}=\mathrm{O})$ of methyl acetate with the hydroxyl group $(\mathrm{OH})$ of 2-Alkoxyethanols (Figs. 5, 6 and 7). The formation of inter-molecular hydrogen bonding between the components of liquid mixtures in the present study has been confirmed by recording of IR spectra of pure liquids and their liquid mixtures.

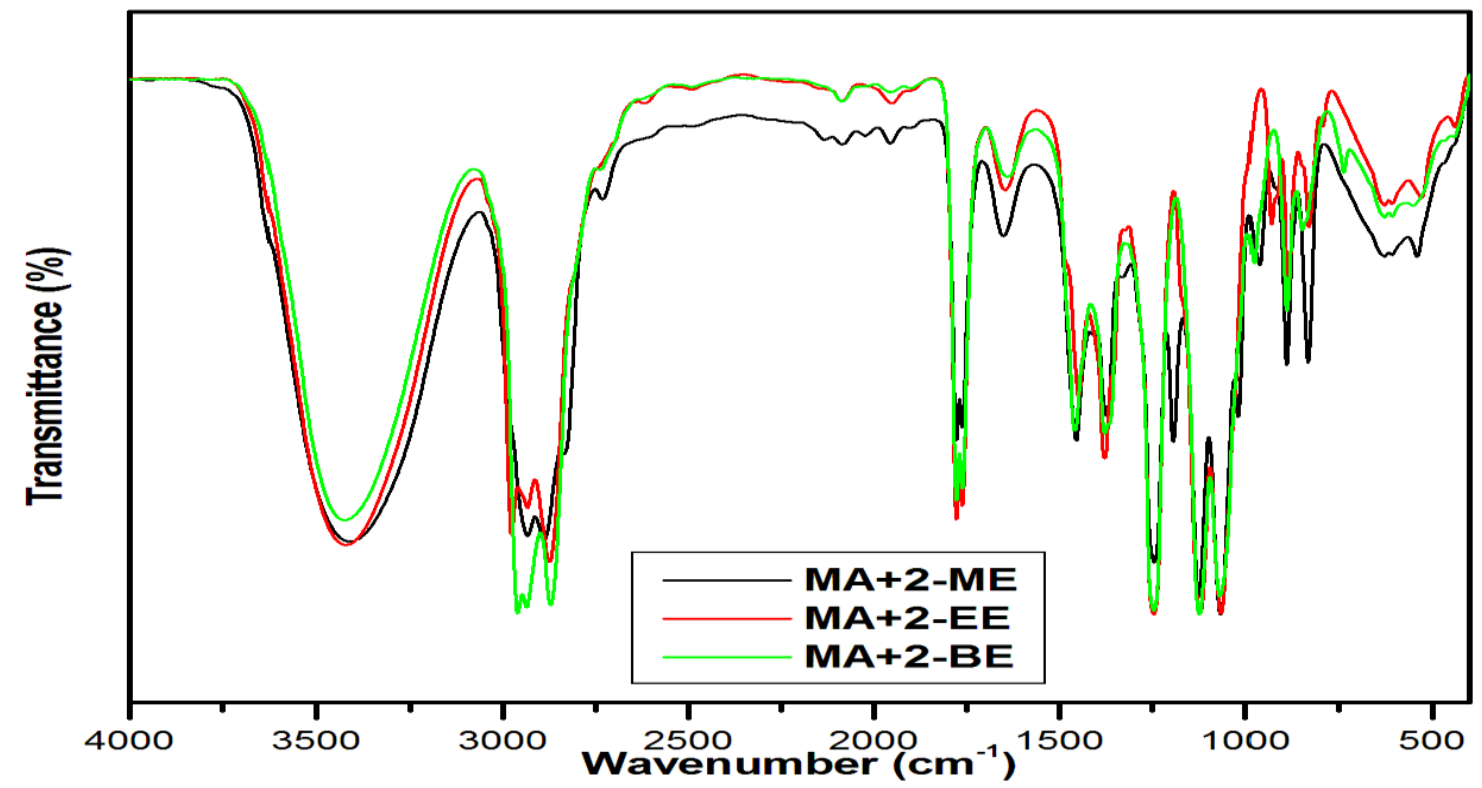

Fig. 4. FTIR spectra of equimolar ratio of Methyl acetate (MA) with 2-Alkoxyethanols

(2-methoxyethanol (2-ME), 2-ethoxyethonal (2-EE) and 2-butoxyethanol (2-BE)) corresponding peaks shift in binary mixtures.

Table 6 FT-IR Spectral band assignments for pure Methyl acetate, 2-Alkoxyethanols and their equimolar binary solutions

\begin{tabular}{|l|c|c|c|}
\hline \multicolumn{1}{|c|}{ Compounds } & Vibration modes & \multicolumn{2}{c|}{ Frequency cm $^{-\mathbf{1}}$} \\
\hline & & $\mathbf{v ~ c m}^{-1}$ & $\boldsymbol{\Delta v} \mathbf{~ c m}^{-\mathbf{1}}$ \\
\hline 2-Methoxyethanol & $\mathrm{O}-\mathrm{H}$ & 3411 & - \\
\hline 2-Ethoxyethanol & $\mathrm{O}-\mathrm{H}$ & 3420 & - \\
\hline 2-Butoxyethanol & $\mathrm{O}-\mathrm{H}$ & 3422 & - \\
\hline Methyl acetate & $\mathrm{CH}_{3}$ asymmetric stretch & 3002 & - \\
\hline & $\mathrm{CH}_{2}$ asymmetric stretch & 2961 & - \\
\hline & $\mathrm{C}=\mathrm{O}$ stretch & 1777 & - \\
\hline & $\mathrm{C}-\mathrm{C}-\mathrm{O}$ stretch & 1247 & - \\
\hline & $\mathrm{O}-\mathrm{CH}_{2}-\mathrm{C}$ asymmetric stretch & 1060 & - \\
\hline Methyl acetate +2-Methoxyethanol & $\mathrm{O}-\mathrm{H}$ & 3412 & 01 \\
\hline
\end{tabular}




\begin{tabular}{|l|c|c|c|}
\hline & $\mathrm{CH}_{3}$ asymmetric stretch & 2974 & 28 \\
\hline & $\mathrm{CH}_{2}$ asymmetric stretch & 2932 & 29 \\
\hline & $\mathrm{C}=\mathrm{O}$ stretch & 1778 & 01 \\
\hline & $\mathrm{C}-\mathrm{C}-\mathrm{O}$ stretch & 1245 & 02 \\
\hline & $\mathrm{O}-\mathrm{CH}_{2}-\mathrm{C}$ asymmetric stretch & 1066 & 06 \\
\hline & $\mathrm{O}-\mathrm{H}$ & 3422 & 02 \\
\hline & $\mathrm{CH}_{3}$ asymmetric stretch & 2976 & 26 \\
\hline & $\mathrm{CH}_{2}$ asymmetric stretch & 2935 & 26 \\
\hline & $\mathrm{C}=\mathrm{O}$ stretch & 1778 & 01 \\
\hline & $\mathrm{C}-\mathrm{C}-\mathrm{O}$ stretch & 1246 & 01 \\
\hline Methyl acetate + 2-Butoxyethanol & O-H & 1065 & 05 \\
\hline & $\mathrm{O}-\mathrm{CH}_{2}-\mathrm{C}$ asymmetric stretch & 3425 & 03 \\
\hline & $\mathrm{CH}_{3}$ asymmetric stretch & 2959 & 43 \\
\hline & $\mathrm{CH}_{2}$ asymmetric stretch & 2935 & 26 \\
\hline & $\mathrm{C}=\mathrm{O}$ stretch & 1778 & 01 \\
\hline & $\mathrm{C}-\mathrm{C}-\mathrm{O}$ stretch & 1246 & 01 \\
\hline & $\mathrm{O}-\mathrm{CH}_{2}-\mathrm{C}$ asymmetric stretch & 1069 & 09 \\
\hline
\end{tabular}

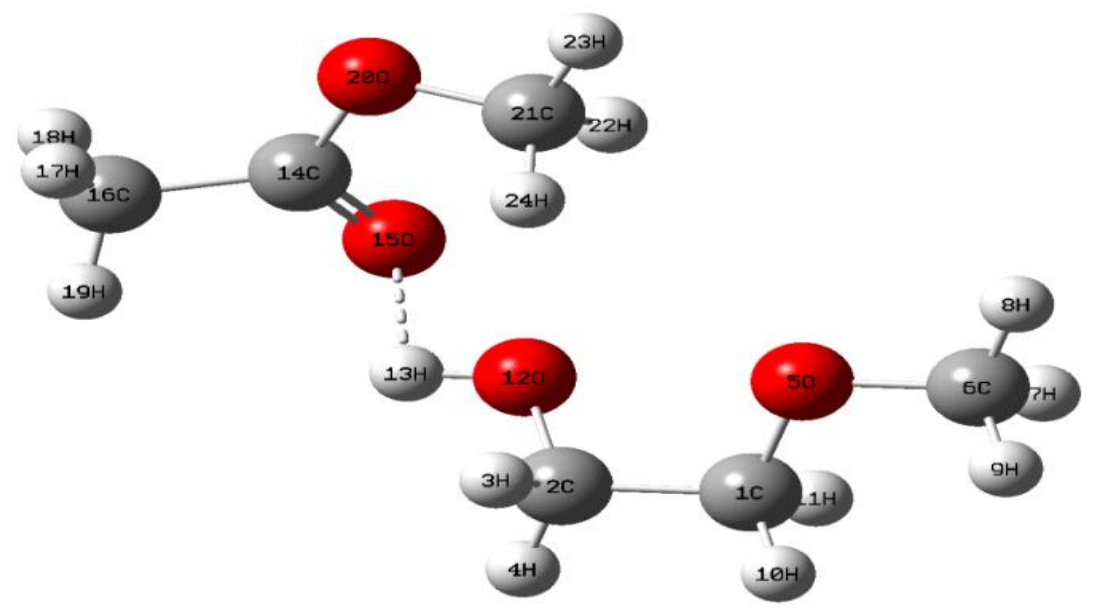

Fig. 5: Hydrogen bond formation of Methyl acetate with 2-methoxyethanol.

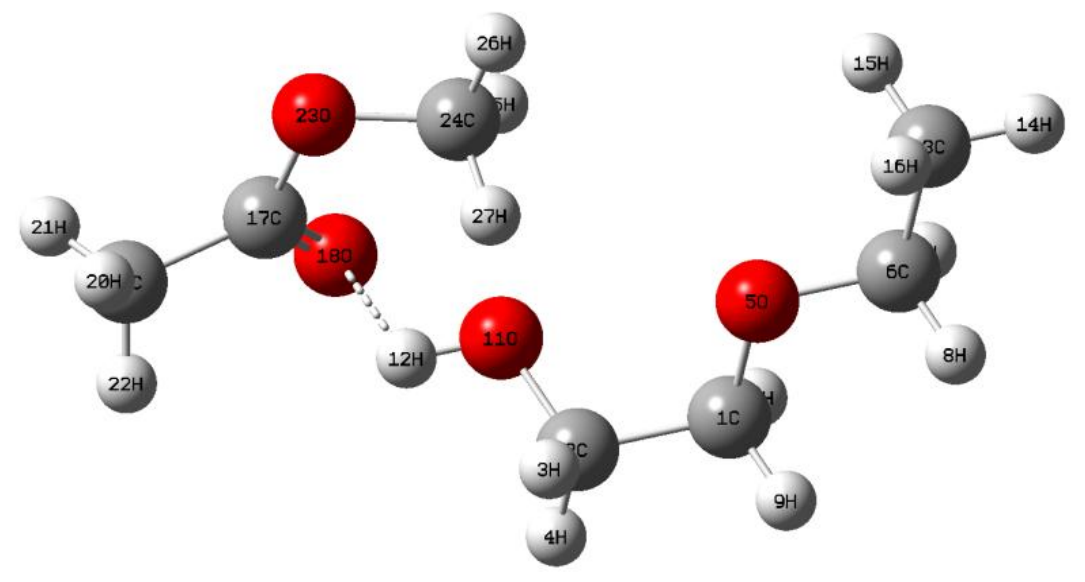

Fig. 6: Hydrogen bond formation of Methyl acetate with 2-ethoxyethanol. 


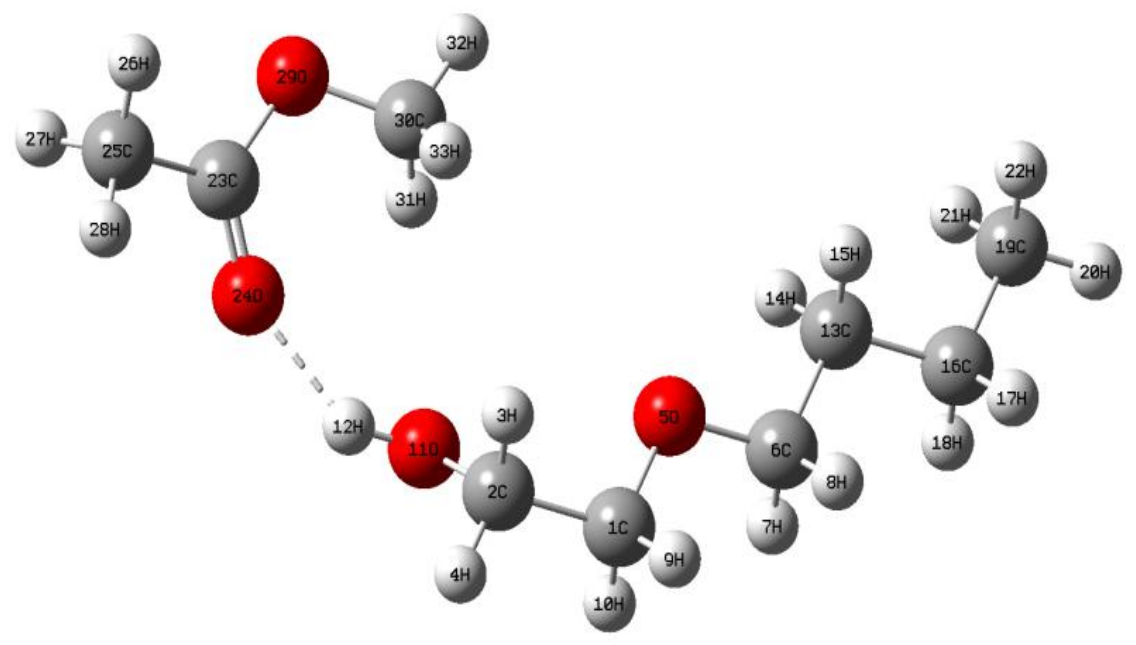

Fig. 7: Hydrogen bond formation of Methyl acetate with 2-butoxyethanol.

\section{CONCLUSION}

The study is concerned with the molecular interaction of Methyl acetate with 2-Alkoxyethanols. The conclusion from the above three systems of molecular interaction with 2-methoxyethanol, 2-ethoxyethonal and 2-butoxyethanol are as follows:

1. Pertaining to the relaxation time, the relaxation time of Pure 2-Alkoxyethanols gets increases with increase of chain length of alcohol molecules (i.e) Methyl acetate with 2-butoxyethanol have more relaxation time than that of 2methoxyethanol and 2-ethoxyethanol. This conclusion was supported by Sivagurunathan et al., [37] in the case of methyl methacrylate with alcohol systems. In our study, Methyl acetate with 2-butoxyethanol is having more chain length when compared to 2-ethoxyethanol and 2-methoxyethanol. The relaxation time is in the order of $\mathrm{MA}+2-\mathrm{BE}>\mathrm{MA}+2-\mathrm{EE}>\mathrm{MA}+2-\mathrm{ME}$.

2. The dielectric constants, the relaxation times, the Kirkwood correlation factors, Bruggeman factor, excess dielectric constant, excess inverse relaxation times, excess Helmholtz free energies of activation, adjustable parameter and standard deviations for esters + alcohols mixtures of various concentrations have been reported. The dielectric parameters show that there are systematic changes with concentration of alkyl chain length of 2-Alkoxyethanols.

3. FT-IR spectra analysis confirms that there exists the H-bond interaction between the participating molecules of the liquids.

\section{REFERENCES}

[1]. A. Pal, H. Kumar, R. Maan, and H. K. Sharma, "Densities and Speeds of Sound of Binary Liquid Mixtures of Some n-Alkoxypropanols with Methyl Acetate, Ethyl Acetate, and n-Butyl Acetate at $T=(288.15,293.15,298.15,303.15$, and 308.15) K," Journal of Chemical \& Engineering Data, vol. 58, no. 2, pp. 225-239, Jan. 2013.

[2]. S. Nallani, S. Boodida, and S. J. Tangeda, "Density and Speed of Sound of Binary Mixtures of N-Methylacetamide with Ethyl Acetate, Ethyl Chloroacetate, and Ethyl Cyanoacetate in the Temperature Interval (303.15 to 318.15) K," Journal of Chemical \& Engineering Data, vol. 52, no. 2, pp. 405-409, Mar. 2007.

[3]. W. Riemenschneider and H. M. Bolt, “Esters, Organic,” Ullmann's Encyclopedia of Industrial Chemistry, Apr. 2005.

[4]. P. Osswald, U. Struckmeier, T. Kasper, K. Kohse-Höinghaus, J. Wang, T. A. Cool, N. Hansen, and P. R. Westmoreland, "Isomer-Specific Fuel Destruction Pathways in Rich Flames of Methyl Acetate and Ethyl Formate and Consequences for the Combustion Chemistry of Esters, " The Journal of Physical Chemistry A, vol. 111, no. 19, pp. 4093-4101, May 2007.

[5]. M. S. Graboski and R. L. McCormick, "Combustion of fat and vegetable oil derived fuels in diesel engines," Progress in Energy and Combustion Science, vol. 24, no. 2, pp. 125-164, Jan. 1998.

[6]. A. Demirbaş, "Yields of oil products from thermochemical biomass conversion processes, " Energy Conversion and Management, vol. 39, no. 7, pp. 685-690, May 1998.

[7]. R. J. Crookes, "Comparative bio-fuel performance in internal combustion engines," Biomass and Bioenergy, vol. 30, no. 5, pp. 461-468, May 2006. 
[8]. P. Jeevanandham, S. Kumar, and P. Periyasamy, "Densities, viscosities, refractive indices and excess properties of ortho- and metachloroaniline with 2-alkoxyethanols at 303.15K, ”Journal of Molecular Liquids, vol. 188, pp. 203-209, Dec. 2013.

[9]. S. Kumar and P. Jeevanandham, "Densities, viscosities, refractive indices and excess properties of aniline and o-anisidine with 2alkoxyethanols at 303.15K," Journal of Molecular Liquids, vol. 174, pp. 34-41, Oct. 2012.

[10]. P. M. Kumar and M. Malathi, "Dielectric relaxation studies of Nylon-11 with phenol derivatives in non-polar solvents using Time Domain Reflectometry, "Journal of Molecular Liquids, vol. 145, no. 1, pp. 5-7, Mar. 2009.

[11]. R. H. Cole, J. G. Berberian, S. Mashimo, G. Chryssikos, A. Burns, and E. Tombari, "Time domain reflection methods for dielectric measurements to $10 \mathrm{GHz}$," Journal of Applied Physics, vol. 66, no. 2, pp. 793-802, Jul. 1989.

[12]. T. M. Aminabhavi and K. Banerjee, "Density, Viscosity, Refractive Index, and Speed of Sound in Binary Mixtures of Methyl Acetate + Ethylene Glycol or + Poly(ethylene glycol) in the Temperature Interval (298.15-308.15) K," Journal of Chemical \& Engineering Data, vol. 43, no. 5, pp. 852-855, Sep. 1998.

[13]. H. Piekarski, A. Piekarska, and K. Kubalczyk, "Volumes, heat capacities, and compressibilities of the mixtures of acetonitrile and 2methoxyethanol," The Journal of Chemical Thermodynamics, vol. 43, no. 9, pp. 1375-1380, Sep. 2011.

[14]. T. M. Aminabhavi and S. K. Raikar, "Thermodynamic Interactions in Binary Mixtures of 2-Methoxyethanol with Alkyl and Aryl Esters at 298.15, 303.15 and 308.15 K," Collection of Czechoslovak Chemical Communications, vol. 58, no. 8, pp. 1761-1776, 1993.

[15]. Z. Begum, P. B. Sandhya Sri, D. B. Karuna Kumar, and C. Rambabu, "Thermodynamic, ultrasonic and FT-IR studies on binary liquid mixtures of anisaldehyde and alkoxyethanols at different temperatures," Journal of Molecular Liquids, vol. 178, pp. 99-112, Feb. 2013.

[16]. N V Sastry, S R Patel \& J George, "Excess thermodynamic and dielectric functions of the binary liquid mixtures of methylmethacrylate + alkoxyethanols (2-methoxyethanol, 2-butoxyethanol) and +1-alcohols (1-butanol, 1-pentanol, 1-heptanol), " Indian Journal of Chemistry, vol. 39A, pp. 1270-1279, 2000.

[17]. R. M. Shirke, Ajay Chaudhari, N. M. More, and P. B. Patil, "Dielectric Measurements on Methyl Acetate + Alcohol Mixtures at (288, 298, 308, and 318) K Using the Time Domain Technique, ” Journal of Chemical \& Engineering Data, vol. 45, pp. 917-919, 2000.

[18]. R H Fattepur, S B Sayyad, N H Ayachit, P.W.Khirade and S C Mehrotra, "Dielectric Relaxation Study of Binary Mixtures of 2-Methoxyathanol in Nitrobenzene and Chlorobenzene Using Time Domain Reflctometry, " IEEE, 978-1-4244-7732-6/10, pp. 1052 -1055, May 2010.

[19]. P. W. Khirade, Ajay Chaudhari, J. B. Shinde, S. N. Helambe and S. C. Mehrotra, "Temperature-Dependent Dielectric relaxation of 2 Ethoxyethanol, Ethanol, and 1-Propanol in Dimethylformamide Solution Using the Time-Domain Technique," Journal of Solution Chemistry, Vol. 28, No. 8, 1999.

[20]. A. C. Kumbharkhane, S. M. Puranik, and S. C. Mehrotra, "Dielectric relaxation of tert-butyl alcohol-water mixtures using a time-domain technique,”J. Chem. Soc., Faraday Trans., vol. 87, no. 10, pp. 1569-1573, 1991.

[21]. S Havriliak; S Negami; Journal of Polymer Science Part C: Polymer Symposia, vol. 14, no. 1, 1966.

[22].F.L.A. Khan, P. Sivagurunathan, S.R.M. Kamil, and S.C. Mehrotra, "Dielectric studies of methyl methacrylate and butyl methacrylate with primary alcohols using time domain reflectometry”, Indian Journal of Pure and Applied Physics., vol. 45, pp. 754-758, 2007.

[23]. J. G. Kirkwood, "Remarks on the Hole Theory of Condensation," The Journal of Chemical Physics, vol. 7, no. 10, pp. 908-911, Oct. 1939.

[24]. S. M. Puranik, A. C. Kumbharkhane, and S. C. Mehrotra, "Dielectric relaxation spectra for N,N-Dimethylacetamide-water mixures using picosecond time domain reflectometry,” Journal of Molecular Liquids, vol. 50, pp. 143-153, Oct. 1991.

[25]. T. Vijaya Krishna and T. Madhu Mohan, "Study of molecular interactions in the polar binary mixtures of N-methyl aniline and alcohols, using excess dielectric and thermodynamic parameters," The Journal of Chemical Thermodynamics, vol. 47, pp. 267-275, Apr. 2012.

[26]. D. Balamurugan, S. Kumar, and S. Krishnan, "Dielectric relaxation studies of higher order alcohol complexes with amines using time domain reflectometry," Journal of Molecular Liquids, vol. 122, no. 1-3, pp. 11-14, Nov. 2005.

[27]. D. A. G. Bruggeman, "Berechnung verschiedener physikalischer Konstanten von heterogenen Substanzen. I. Dielektrizitätskonstanten und Leitfähigkeiten der Mischkörper aus isotropen Substanzen," Annalen der Physik, vol. 416, no. 7, pp. 636-664, 1935.

[28]. V. A. Rana, A. D. Vyas, and S. C. Mehrotra, "Dielectric relaxation study of mixtures of 1-propanol with aniline, 2-chloroaniline and 3chloroaniline at different temperatures using time domain reflectometry," Journal of Molecular Liquids, vol. 102, no. 1-3, pp. 379-391, Jan. 2003.

[29]. A. C. Kumbharkhane, S. M. Puranik, and S. C. Mehrotra, "Dielectric relaxation studies of aqueous N,N-dimethylformamide using a picosecond time domain technique, ” Journal of Solution Chemistry, vol. 22, no. 3, pp. 219-229, Mar. 1993.

[30]. T. Vishwam, K. Parvateesam, S. SreehariSastry, and V. R. K. Murthy, "Temperature-dependent microwave dielectric relaxation studies of hydrogen bonded polar binary mixtures of propan-1-ol and propionaldehyde," Spectrochimica Acta Part A: Molecular and Biomolecular Spectroscopy, vol. 114, pp. 520-530, Oct. 2013.

[31]. T. V. Krishna and S. S. Sastry, "Dielectric and Thermodynamic Studies on the Hydrogen Bonded Binary System of Isopropyl Alcohol and Aniline," Journal of Solution Chemistry, vol. 39, no. 9, pp. 1377-1393, Aug. 2010.

[32]. S. C. Mehrotra and J. E. Boggs, "Effect of collision-induced phase shifts on the linewidths and line shifts of rotational spectral lines," The Journal of Chemical Physics, vol. 66, no. 12, pp. 5306-5312, Jun. 1977.

[33]. T. V. Krishna and S. S. Sastry, "Dielectric And Thermodynamic Studies On The Hydrogen Bonded Binary System Of Isopropyl Alcohol And Aniline," Journal Of Solution Chemistry, vol. 39, no. 9, pp. 1377-1393, Aug. 2010.

[34]. G. Parthipan, G. Arivazhagan, and T. Thenappan, "Dielectric and thermodynamic studies on a binary mixture of anisole with butyric or caprylic acid," Philosophical Magazine Letters, vol. 88, no. 2, pp. 125-136, Feb. 2008.

[35]. T. M. Mohan, S. S. Sastry, and V. R. K. Murthy, "Thermodynamic, Dielectric and Conformational Studies on Hydrogen Bonded Binary Mixtures of Propan-1-ol with Methyl Benzoate and Ethyl Benzoate,” Journal of Solution Chemistry, vol. 40, no. 1, pp. 131-146, Dec. 2010.

[36]. N. L. Alpert, W. E. Keiser, H. A. Szymanski, and J. H. Shaw, "IR-Theory and Practice of Infrared Spectroscopy,” Physics Today, vol. 27, no. 5, pp. 47-49, May 1974.

[37]. P. Sivagurunathan, K. Dharmalingam, K. Ramachandran, B. Prabhakar Undre, P. W. Khirade, and S. C. Mehrotra, "Dielectric studies on binary mixtures of ester with alcohol using time domain reflectometry," Journal of Molecular Liquids, vol. 133, no. 1-3, pp. 139-145, Mar. 2007. 


\section{AUTHORS PROFILE}

Dr. S. Kumar completed his M.Sc (Physics), M.Phil and Ph.D in 1986, 1988 and 2001 respectivelty. He is currently working as Associate Professor in the department of Physics, Annamalai University, Chidambaram. He has published more than 30 Papers in reputed international journals / conferences. His main research work focuses on Dielectric studies of molecular interaction in liquids. He has 30 years of teaching and research experience.

Mr. L. Guganathan has completed his M.Sc Physics and going to submit the Ph.D thesis in 2013 and 2018 respectively. He is currently doing his Ph.D (Physics) in the Department of Physics, Annamalai University, Chidambaram. He has 03 research papers in the international journals.

Dr. M. Malathi is the professor of physics at Centre for Crystal Growth, Vellore Institute of Technology. My research is aimed at understanding the structure, properties and the H-bond interactions of the complex bio

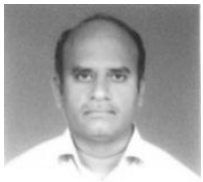
molecules using dielectric spectroscopy, FTIR and computational method. And, we also focus our research on the synthesis of hybrid polymers and aromatic polymers by blends \& grafting methods for the applications of solar cell, flame retardant, optical properties, and hydrophobic, thermal and mechanical properties. To elevate our research work, we received funding from DST \& DRDO Government of India.

Dr. A.Mohan is a PDF candidate in microwave and energy engineering at Kunming University of Science and Technology, Kunming, China. His main research interests include dielectric materials, ceramic-polymer composites, and dielectric measurements for high temperature applications in aircraft devices. He has authored and co-authored in 4 peer-reviewed papers.

Mr. R. Amalanathan has completed his M.Sc Physics and going to submit the Ph.D thesis in 2015 and 2019 respectively. He is currently doing his Ph.D (Physics) in the Department of Physics, Annamalai University, Chidambaram. He has presented 05 national and international Conferences.
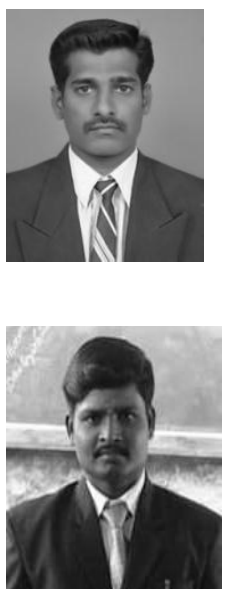